(1)

CrossMark

\title{
Obstructive sleep apnoea and exercise functional capacity: time to move?
}

\author{
Núria Farré ${ }^{1}$ and Geraldo Lorenzi-Filho ${ }^{2}$
}

Affiliations: ${ }^{1}$ Heart Failure Programme, Dept of Cardiology, Hospital del Mar, Heart Diseases Biomedical Research Group, Hospital del Mar Medical Research Institute (IMIM), Dept of Medicine, Universitat Autònoma de Barcelona, Barcelona, Spain. ${ }^{2}$ Sleep Laboratory, Pulmonary Division, Instituto do Coração, Departamento de Medicina, Universidade de São Paulo, São Paulo, Brazil.

Correspondence: Geraldo Lorenzi-Filho, Sleep Laboratory, Pulmonary Division, Instituto do Coração, Av. Dr. Enéas de Carvalho Aguiar, 44 - Pinheiros, São Paulo - SP, 05403-900, Brazil.

E-mail: geraldo.lorenzidgmail.com

@ERSpublications

Patients with sleep apnoea have reduced exercise capacity. Should exercise programmes be included in their routine clinical management? http://ow.ly/TukR30ksqjG

Cite this article as: Farré N, Lorenzi-Filho G. Obstructive sleep apnoea and exercise functional capacity: time to move? Eur Respir J 2018; 51: 1801031 [https://doi.org/10.1183/13993003.01031-2018].

Obstructive sleep apnoea (OSA) is defined by repetitive episodes of obstructive respiratory events, characterised by marked reduction (hypopnoea) or cessation of respiration (apnoea) due to upper airway obstruction during sleep. Each respiratory event leads to episodes of asphyxia and progressive but futile generation of excessive negative intrathoracic pressure. The patient is typically self-rescued by an arousal from sleep that leads to opening of the airway and resumption of breathing [1]. OSA is common in the general population across the whole human life span from infants to the elderly [2]. There is good evidence built over the past 30 years that OSA may trigger a cascade of mechanisms that are harmful to the cardiovascular and metabolic system, including sympathetic over activity, oxidative stress, endothelial dysfunction and insulin resistance. OSA is also associated with hypertension, arrhythmias, progression of atherosclerosis and increased cardiovascular mortality due to acute myocardial infarction and stroke [3-6]. Despite all these evidence, the impact of OSA on cardiorespiratory fitness (CRF) is controversial. This is an important question because low levels of CRF have been associated with a high risk of cardiovascular disease and all-cause mortality [7-9]. CRF is a potentially stronger predictor of mortality than established cardiovascular risk factors $[9,10]$. Although CRF can be quantified by different means, including metabolic equivalents (METS) or peak oxygen consumption $\left(V^{\prime} \mathrm{O}_{2}\right.$ peak), the evidence available so far shows that, irrespective of the method used, low CRF is associated with worse prognosis [9].

In this issue of the European Respiratory Journal, MENDELSON et al. [11] report a systematic review and meta-analysis to clarify the possible alterations of $V^{\prime} \mathrm{O}_{2}$ peak in patients with OSA. When all relevant studies were compiled, the authors found that $V^{\prime} \mathrm{O}_{2}$ peak is significantly lower in OSA patients than proper controls (mean difference $-2.7 \mathrm{~mL} \cdot \mathrm{kg}^{-1} \cdot \mathrm{min}^{-1}, 95 \% \mathrm{CI}-4.0$ to $-1.4 ; \mathrm{p}<0.001 ; \mathrm{n}=850$ ) and that mean $\pm \mathrm{SD} V^{\prime} \mathrm{O}_{2}$ peak is $90.7 \pm 21.0 \%$ of predicted in OSA patients. Subgroup analysis showed that both younger ( $<50$ years) and older ( $>50$ years) OSA patients had lower $V^{\prime} \mathrm{O}_{2}$ peak compared to controls. Interestingly, leaner patients (body mass index (BMI) $<30 \mathrm{~kg} \cdot \mathrm{m}^{-2}$ ) had the highest difference in $V^{\prime} \mathrm{O}_{2}$ peak compared to controls $\left(-4.1 \mathrm{~mL} \cdot \mathrm{kg}^{-1} \cdot \mathrm{min}^{-1} ; \mathrm{p}<0.001\right)$. Low $V^{\prime} \mathrm{O}_{2}$ peak could help to explain the impairment seen in the overall quality of life and in the physical components in patients with OSA [12-16]. The interesting data reported by Mendelson et al. [11] have been collected from previously published clinical studies and therefore reflect some limitations found commonly in clinical research. Indeed, as it is often seen in cardiovascular and OSA studies [17-21], women and the elderly were under-represented [11]. This limitation is relevant 
because previous research has shown that the association of OSA with significant reductions in quality of life scores is independent of sleepiness and comorbidities in men less than 69 years old, but not in men older than 70 years [15]. Similarly, women with OSA showed reduced physical scores in quality of life scales compared to men $[12,16]$, which could be associated with differences in $V^{\prime} \mathrm{O}_{2}$ peak. Finally, levels of physical activity, which were unknown in the majority of available studies, could have affected the results on exercise capacity seen by MeNDELSON et al. [11]. In a study carried out in male veterans, low CRF was associated with mortality after adjusting for clinical variables and remained a strong predictor of mortality after further adjusting for physical activity. On the other hand, physical activity was not a significant predictor of mortality after adjusting for CRF [8]. Interestingly, MENDELSON et al. [22] have recently showed in a meta-analysis that OSA patients presented low levels of physical activity, with a mean number of steps per day of 5388 (95\% CI 3831-6945), far below the recommended threshold of 10000 steps per day. Moreover, exercise training was associated with significant decrease in apnoea-hypopnoea index, reduction in subjective sleepiness and, notably, increase in $V^{\prime} \mathrm{O}_{2}$ peak but no change in BMI [22]. Although the specific mechanisms by which OSA can affect exercise capacity are unknown, it is possible that low levels of physical activity may contribute to low CRF observed in patients with OSA.

In conclusion, the information currently available indicates that maximal exercise capacity is reduced in patients with OSA. While this reduction might signal an increased comorbidity and mortality risk, it also offers the opportunity to implement clinical strategies to improve CRF and potentially improve prognosis and quality of life. Specifically, the recent studies by MENDELSON et al. [11,22] raise the interesting question of whether followed-up physical exercise programmes should be more actively included in the clinical routine management of patients with OSA.

Conflict of interest: None declared.

\section{References}

$1 \quad$ Lévy P, Kohler M, McNicholas WT, et al. Obstructive sleep apnoea syndrome. Nat Rev Dis Prim 2015 ; 1 : 15015.

2 Heinzer R, Vat S, Marques-Vidal P, et al. Prevalence of sleep-disordered breathing in the general population: the HypnoLaus study. Lancet Respir Med 2015; 3: 310-318.

3 Dong J-Y, Zhang Y-H, Qin L-Q. Obstructive sleep apnea and cardiovascular risk: meta-analysis of prospective cohort studies. Atherosclerosis 2013; 229: 489-495.

4 Gozal D, Ham SA, Mokhlesi B. Sleep apnea and cancer: analysis of a nationwide population sample. Sleep 2016; 39: $1493-1500$

5 Drager LF, McEvoy RD, Barbe F, et al. INCOSACT Initiative (International Collaboration of Sleep Apnea Cardiovascular Trialists). Sleep apnea and cardiovascular disease. Circulation 2017; 136: 1840-1850.

6 Mediano O, Lorenzi-Filho G, García-Río F. Obstructive sleep apnea and cardiovascular risk: from evidence to experience in cardiology. Rev Española Cardiol (English Ed) 2018; 71: 323-326.

7 Kokkinos P, Myers J, Kokkinos JP, et al. Exercise capacity and mortality in black and white men. Circulation 2008; 117: 614-622.

8 Davidson T, Vainshelboim B, Kokkinos P, et al. Cardiorespiratory fitness versus physical activity as predictors of all-cause mortality in men. Am Heart J 2018; 196: 156-162.

9 Ross R, Blair SN, Arena R, et al. Importance of assessing cardiorespiratory fitness in clinical practice: a case for fitness as a clinical vital sign: a scientific statement from the American Heart Association. Circulation 2016; 134: e653-e699.

10 Myers J, Prakash M, Froelicher V, et al. Exercise capacity and mortality among men referred for exercise testing. $N$ Engl J Med 2002; 346: 793-801.

11 Mendelson M, Marillier M, Bailly S, et al. Maximal exercise capacity in patients with obstructive sleep apnoea syndrome: a systematic review and meta-analysis. Eur Respir J 2018; 51: 1702697.

12 Appleton S, Gill T, Taylor A, et al. Influence of gender on associations of obstructive sleep apnea symptoms with chronic conditions and quality of life. Int J Environ Res Public Health 2018; 15: 930.

13 Moore P, Bardwell WA, Ancoli-Israel S, et al. Association between polysomnographic sleep measures and health-related quality of life in obstructive sleep apnea. J Sleep Res 2001; 10: 303-308.

14 Bjornsdottir E, Keenan BT, Eysteinsdottir B, et al. Quality of life among untreated sleep apnea patients compared with the general population and changes after treatment with positive airway pressure. J Sleep Res 2015; 24: $328-338$.

15 Appleton SL, Vakulin A, McEvoy RD, et al. Undiagnosed obstructive sleep apnea is independently associated with reductions in quality of life in middle-aged, but not elderly men of a population cohort. Sleep Breath 2015; 19: 1309-1316

16 Tasbakan MS, Gunduz C, Pirildar S, et al. Quality of life in obstructive sleep apnea is related to female gender and comorbid insomnia. Sleep Breath 2018; in press [https://doi.org/10.1007/s11325-018-1621-y].

17 Pilote L, Dasgupta K, Guru V, et al. A comprehensive view of sex-specific issues related to cardiovascular disease. CMAJ 2007; 176: S1-S44.

18 Rich MW, Chyun DA, Skolnick AH, et al. Knowledge gaps in cardiovascular care of the older adult population. Circulation 2016; 133: 2103-2122.

19 Braley TJ, Dunietz GL, Chervin RD, et al. Recognition and diagnosis of obstructive sleep apnea in older Americans. J Am Geriatr Soc 2018; in press [https://doi.org/10.1111/jgs.15372].

20 Mallampalli MP, Carter CL. Exploring sex and gender differences in sleep health: a Society for Women's Health Research report. J Women's Health 2014; 23: 553-562. 
21 Han MK, Arteaga-Solis E, Blenis J, et al. Female sex and gender in lung/sleep health and disease: increased understanding of basic biological, pathophysiological and behavioral mechanisms leading to better health for female patients with lung disease. Am J Respir Crit Care Med 2018; in press [https://doi.org/10.1164/rccm. 201801-0168WS].

22 Mendelson M, Bailly S, Marillier M, et al. Obstructive sleep apnea syndrome, objectively measured physical activity and exercise training interventions: a systematic review and meta-analysis. Front Neurol 2018; 9: 73. 